\title{
Highly Selective Copper and Nickel Separation and Recovery from Electroplating Sludge in Light Industry
}

\author{
Wei Xu' ${ }^{1}$ Wei Liu ${ }^{1}$, Haochen $\mathrm{Zhu}^{1}$, Jingcheng $\mathrm{Xu}^{1 *}$, \\ Guangming $\mathrm{Li}^{1 * *}$, Dan $\mathrm{Fu}^{2}$, Lan Luo ${ }^{1}$ \\ 'State Key Laboratory of Pollution Control and Resources Reuse, \\ College of Environmental Science and Engineering, \\ Tongji University, Shanghai, People's Republic of China \\ ${ }^{2}$ Shanghai Light Industry Research Institute, \\ Shanghai Engineering Research Center for Heavy Metal Pollution Control and Reuse, \\ Shanghai, People's Republic of China
}

Received: 30 April 2014

Accepted: 3 August 2014

\begin{abstract}
Electroplating sludge and associated waste products comprise complex mixtures of metallic elements and may cause serious environmental pollution if discharged without treatment. An effective light industrial process is modified to selectively extract and recover copper and nickel from electroplating sludge. The procedure was developed on a laboratory scale and validated in a small pilot plant. Extraction yields of greater than $95 \%$ for $\mathrm{Cu}$ and $\mathrm{Ni}$ are achieved under optimum leaching conditions. To selectively recover copper and nickel from the leaching solution, they were extracted by N902 in kerosene, followed by selective stripping using sulfuric acid. The overall recoveries of copper and nickel were $93.6 \%$ and $88.9 \%$, respectively, via a fast, simple, and inexpensive process. Partial recovery of ammonia in the process enables some cost savings. The technology can be used for metal resource recovery from solid wastes containing copper and nickel.
\end{abstract}

Keywords: ammonia/ammonium leaching, copper, nickel, electroplating sludge, resource reuse

\section{Introduction}

Chemical precipitation is the most common treatment process for the removal of heavy metals from wastewater $[1,2]$. Electroplating sludge (EPS) is a heavy metals-bearing byproduct of the electroplating industry. Most EPS produced by electroplating is a mixture consisting of various metals such as copper, nickel, zinc, iron, and chromium, in a complicated liquid-solid mixture [3]. Some of these heavy metals have relatively high densities, and are poisonous in

*e-mail: xujick@tongji.edu.cn

**e-mail: ligm@tongji.edu.cn low quantities. EPS is recognized worldwide as hazardous waste [4]. Spreading EPS on fields drastically increases the heavy metal content of the soil, and associated risks of groundwater pollution, increased toxic metal mobility, plant toxicity, and metal contamination throughout the food chain $[5,6]$. Consumption of heavy metal-contaminated foods is associated with suppression of the immune system, reduced fertility, and even acute poisoning at high concentrations [7]. Inappropriate treatment of EPS poses hazards to humans, animals, fish, the environment, and the wider ecosystem. This also represents results in considerable waste of valuable resources. In China, more than 100,000 tons of valuable heavy metals are lost every year in the 
Table 1. The chemical composition of ES (dry basis) (\%).

\begin{tabular}{|c|c|c|c|c|c|c|c|c|}
\hline Metals & $\mathrm{Cu}$ & $\mathrm{Ni}$ & $\mathrm{Fe}$ & $\mathrm{Mg}$ & $\mathrm{Ca}$ & $\mathrm{Zn}$ & $\mathrm{Al}$ & $\mathrm{Cr}$ \\
\hline$\%$ Content & 1.45 & 3.01 & 1.40 & 0.01 & 11.1 & 0.03 & 8.25 & 0.12 \\
\hline
\end{tabular}

form of EPS [8]. To ensure environmental protection and sustainable development, achieving recovery and recycling of heavy metals from EPS economically is of great importance.

In recent decades, conventional methods for the recovery of valuable metals focused on leaching [9-11] and solidification technologies [12-14]. However, when acid leaching is applied to EPS, $\mathrm{Cu}, \mathrm{Ni}, \mathrm{Zn}, \mathrm{Cr}$, and $\mathrm{Fe}$ all dissolve into the leaching solution $[3,15]$, which makes subsequent separation of the metals difficult. Mineral acids are also strongly corrosive, and readily corrode the equipment used, which increases process costs. Selective separation and recovery of valuable metals $(\mathrm{Zn}, \mathrm{Cu}$, and $\mathrm{Ni}$ ) is therefore critical to the recovery of other heavy metals from EPS. Ammonia and ammonium solutions have low cost, high selectivity, and are less corrosive, and may be better leaching reagents [16].

Ammonia leaching has been used in the treatment of EPS, and is the first step of EPS recycling. Some ammonia leaching systems that are used to extract specific metals (Ni or $\mathrm{Cu}$ ) from certain types of sludge can achieve leaching efficiencies greater than $90 \%$ for individual metals [17]. Combination technologies have since been developed, which allow the recovery of valuable metals from mixed sludges $[18,19]$. Leaching efficiencies of $\mathrm{Ni}, \mathrm{Cu}$, and $\mathrm{Zn}$ reached $80.25,77.42$, and $91.07 \%$, respectively. The combined processes may be used for recovery of copper and nickel from mixed EPS, although current technologies have some problems relating to the technical complexity, low metal recoveries, and high processing costs. The development of a simple, economical ammonia leaching technology is necessary.
In this paper we focus on an ammonia leaching-extraction-stripping technology to recover $\mathrm{Cu}$ and $\mathrm{Ni}$ from EPS. The influencing factors (reagent concentration, time, and phase ratio) of each step in the process are discussed. This method provides the basis for resource recovery from EPS, and can serve as a reference for reuse and recycling of other solid wastes containing heavy metals.

\section{Materials and Methods}

\section{Chemicals and Sludge Sample}

EPS was collected from an electroplating factory in Taicang, Jiangsu Province, China. The sludge was green and had a $\mathrm{pH}$ of 8.3 (measured by $\mathrm{pH}$ meter) and water content of $80.5 \%$ [20]. All reagents used in the study were of analytical grade and the water was deionized.

\section{Experimental Procedures}

The sludge was dried to constant weight at $105^{\circ} \mathrm{C}$ and then milled. A sample containing $0.8-1.0 \mathrm{~mm}$ particles was selected for experimentation. The EPS sample $(0.25$ g) was dissolved in aqua regia (concentrated $\mathrm{HCl}$ and $\mathrm{HNO}_{3}$ at a volumetric ratio of $3: 1$ ). The solution compositions were quantified by inductively coupled plasma-optical emission spectrometry (ICP-AES) (Agilent 720ES, USA) and are presented in Table 1. Metals with less than $0.1 \%$ dry mass in the EPS were neglected and not evaluated further in this study without impacting the conclusions.

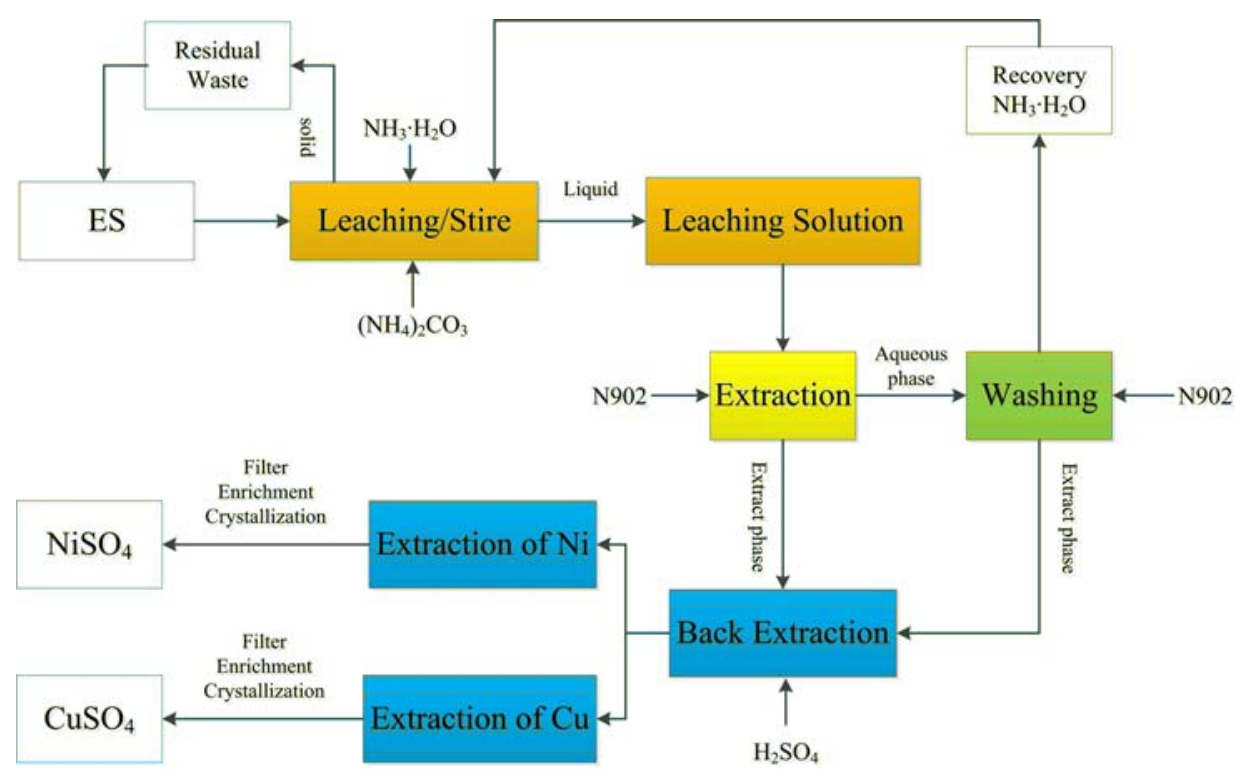

Fig. 1. Ammonia leaching-extraction-stripping schematic process for nickel and copper recovery. 
Fig. 1 shows the proposed process flow diagram for recovery of heavy metal from EPS. The EPS (100 g dry basis) is leached in different volumes of leaching solution $(200,160,140$, and $110 \mathrm{~mL})$ in a four-stage extraction in a $500 \mathrm{~mL}$ tapered bottle. After extracting each fraction, the sludge suspensions were magnetically stirred (2000 rpm, $90 \mathrm{~min}$ ) and filtered through a $2.5 \mu \mathrm{m}$ filter membrane. Copper and nickel were then extracted with N902, a hydroxyoxime extractant, and the raffinate was water washed to recycle free ammonia. Finally, copper and nickel were back-extracted (stripped) from N902 at room temperature using sulfuric acid. Optimum conditions for leaching, extraction, washing, and stripping were determined.

The relevant extraction equations are as follows:

$$
\begin{aligned}
& \mathrm{Ni}^{2+}+6 \mathrm{NH}_{3}+\mathrm{CO}_{3}^{2-} \rightarrow \mathrm{Ni}\left(\mathrm{NH}_{3}\right)_{6} \mathrm{CO}_{3} \\
& \mathrm{Cu}^{2+}+4 \mathrm{NH}_{3}+\mathrm{CO}_{3}^{2-} \rightarrow \mathrm{Cu}\left(\mathrm{NH}_{3}\right)_{4} \mathrm{CO}_{3}
\end{aligned}
$$

\section{Chemical and Data Analysis}

The concentration of metal ions was detected by ICPAES. Samples were first treated by microwave digestion and then filtered through $2.5 \mu \mathrm{m}$ filter membrane. Free ammonia was measured spectrophotometrically using
Nessler's reagent according to a standard method (HJ5352009). All measurements were repeated at least three times to ensure consistency. Mean values are presented in the Figures and Tables.

\section{Results and Discussion}

\section{Effect of Leaching Parameters on the Extent of Leaching of Copper and Nickel}

An ammonia/ammonium leaching solution was used to extract copper and nickel from EPS. As shown in Fig. 2, parameters such as the concentration of leaching reagents, liquid-solid (L/S) ratio, leaching time, and number of leaching stages were optimized.

Ammonia is an effective solvent for the recovery of copper and nickel. As shown in Fig. 2A, leaching efficiencies of all metals increased with increasing mass fraction of ammonia. Once the mass fraction of ammonia reached $20 \%$, leaching efficiencies of copper and nickel stabilized at a maximum value. Further increases in ammonia concentration led to waste of reagents and ammonia volatilization, which may also cause environmental problems [21].
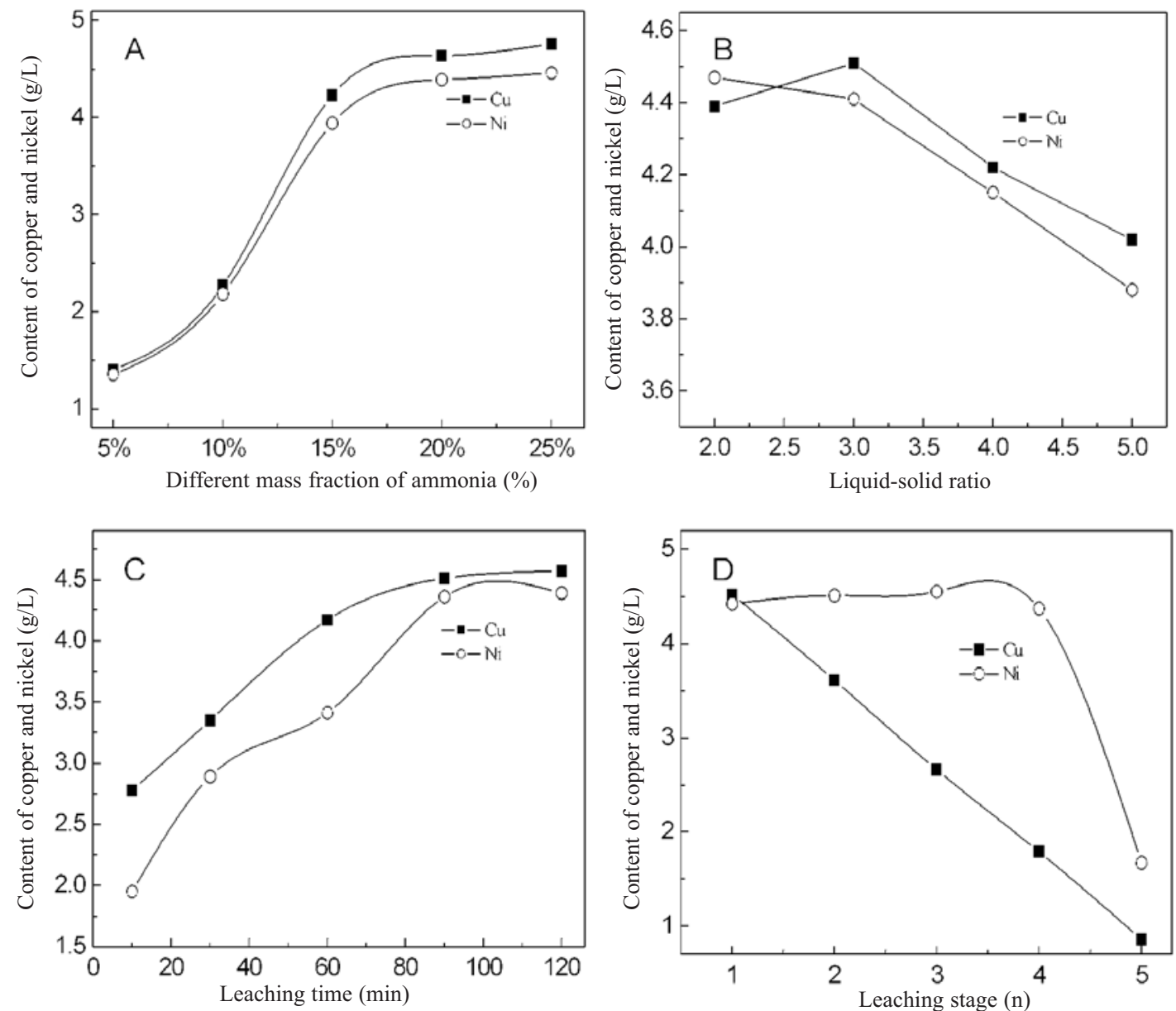

Fig. 2. Effects of different mass fraction of ammonia (A), liquid-solid ratio (B), leaching time (C), and leaching stage (D) on the extent of leaching of each metal. (Conditions: $\mathrm{m}_{\mathrm{ES}}=100 \mathrm{~g}$, Stirring speed $=2000 \mathrm{rpm}, \mathrm{T}=25 \pm 2^{\circ} \mathrm{C}, \mathrm{pH}=10.8-11.2 . \mathrm{A}$ ) $\mathrm{L} / \mathrm{S}=3: 1, \mathrm{t}=1.5 \mathrm{~h}$; B) Mass fraction of ammonia $=20 \%, t=1.5 \mathrm{~h} ; \mathrm{C}) \mathrm{L} / \mathrm{S}=3: 1$, Mass fraction of ammonia $=20 \%$; $) \mathrm{L} / \mathrm{S}=3: 1$, Mass fraction of ammonia $=20 \%, \mathrm{t}=1.5 \mathrm{~h}$ ). 
Table 2. The metals concentrations in the leaching solution $(\mathrm{g} / \mathrm{L})$.

\begin{tabular}{|c|c|c|c|c|c|c|c|c|}
\hline Metals & $\mathrm{Cu}$ & $\mathrm{Ni}$ & $\mathrm{Al}$ & $\mathrm{Ca}$ & $\mathrm{Fe}$ & $\mathrm{Mg}$ & $\mathrm{Zn}$ & $\mathrm{Cr}$ \\
\hline Content (g/L) & 2.28 & 4.56 & 0.13 & 0.27 & 0.05 & $\mathrm{ND}$ & $\mathrm{ND}$ & 0.08 \\
\hline Leaching Rate (\%) & 96.03 & 95.35 & 0.89 & 1.36 & 2.09 & $\mathrm{ND}$ & $\mathrm{ND}$ & 3.33 \\
\hline
\end{tabular}

A mass fraction of $20 \%$ ammonia was therefore selected for subsequent experiments.

The effect of the L/S ratio on the leaching of copper and nickel is shown in Fig. 2B. With increasing L/S ratio, the concentrations of copper and nickel in the leaching solution declined and this effect was more pronounced for the leaching of nickel. At $\mathrm{L} / \mathrm{S}=2: 1$ the concentration of ammonia in the solution was less than the theoretical requirement. When the leach solution metal concentrations were higher, L/S separation performance was poor, which prevented subsequent recovery of ammonia. However, as L/S ratio increased from 2:1 to 3:1, the copper and nickel concentrations remained constant, while the separation of the leaching slurry significantly improved. Because increasing the $\mathrm{L} / \mathrm{S}$ ratio caused a sharp decline in the leaching efficiencies of copper and nickel, an optimum L/S ratio of 3:1 was selected for the following experiments.

Fig. 2C shows the concentrations of copper and nickel in the leaching solution for different leaching times. These results illustrate that the leaching rates of these metals are similar: the copper content of leaching solution was similar to that of nickel, even extending the leaching time. The ammonia leaching process is essentially limited by the liquid-solid phase reaction [22], so as the reaction proceeded, leaching of the heavy metals gradually reached an equilibrium. Based on these results, $1.5 \mathrm{~h}$ was identified as the optimum reaction time.

The number of leaching stage also played a significant role in metal recovery (Fig. 2D), and had a greater effect than any other factor. By increasing the number of leaching stages, the concentration of copper in the leach solution gradually decreased. Nickel leaching efficiency showed a decrease after more than four leaching stages, suggesting ammonia showed better selectivity for nickel. To improve the leaching of nickel, the number of leaching stages must be strictly controlled. These results are consistent with those of Muzenda et al. [23], who reported that the recovery of nickel and copper from solid waste was greatly influenced by the concentration of ammonia, leaching time, number of leaching stages, and $\mathrm{pH}$. Our results were not completely in agreement with those of other research [24, 25], but the slight differences may be attributed to the use of different leaching agents.

The concentrations of the metals in the leaching solution were shown in Table 2. The extent of leaching exceeded $95 \%$ at room temperature. The optimum conditions are: $\mathrm{L} / \mathrm{S}$ of $3: 1, \mathrm{pH}$ of 10.8 11.2, ammonia concentration of $20 \%$, extraction time of $1.5 \mathrm{~h}$, stirring speed of $2000 \mathrm{rpm}$, and four stages of extraction. Impurities such as $\mathrm{Mg}, \mathrm{Zn}$, and $\mathrm{Al}$ hardly leached, and reported to leach- ing residue [26]. These experimental results lay a good foundation for future studies into the recovery of copper and nickel.

\section{Effect of Extraction Parameters on the Extraction Rate of Copper and Nickel}

N902 and sulfonated kerosene were chosen as extractant and diluent, respectively. Experiment parameters evaluated included extractant concentration (N902 volume fraction), aqueous-to-organic volumetric phase ratio $(\mathrm{A} / \mathrm{O})$, extraction time, and the number of extraction degree (n) to achieve selective separation of copper and nickel from the leaching solution. The results are shown in Fig. 3.

As shown in Fig. 3, it was obvious that these experimental parameters influenced the extraction of nickel more than that of copper. The reason is that N902 is a hydroxyoxime extractant $[27,28]$. The donor atoms of the hydroxyoxime extractant are $\mathrm{N}$ and $\mathrm{O}$, and the stability of a chelate formed between first-row transition divalent metal ions follows the order: $\mathrm{Cu}^{2+}>\mathrm{Ni}^{2+}>\mathrm{Fe}^{2+}>\mathrm{Mn}^{2+}$ [29]. $\mathrm{Cu}^{2+}$ combines more easily with $\mathrm{N} 902$ than $\mathrm{Ni}^{2+}$. The optimum experimental conditions were therefore determined by a mathematical treatment of the experimental data. The results showed that the optimum extraction conditions were 30 vol. $\%$ extractant concentration, $\mathrm{A} / \mathrm{O}$ of 3 , extraction time of $10 \mathrm{~min}$, and three stages of extraction. As shown in Table 3, under optimum conditions N902 simultaneously extracts copper and nickel from the ammonia-leaching solution, with the extent of extraction of copper and nickel reaching 99.5 and $98.1 \%$, respectively. Similar results have been reported by Zhang et al. [30]. The other metals remain mostly in the raffinate.

Because metal extraction by $\mathrm{N} 902$ occurs by chelation, the reaction can be written as:

$$
2 \mathrm{RH}_{(\mathrm{O})}+\mathrm{M}_{(\mathrm{A})}^{2+} \fallingdotseq \mathrm{MR}_{2(\mathrm{O})}+2 \mathrm{H}^{2+}{ }_{(\mathrm{A})}
$$

...where RH and $\mathrm{M}$ are the hydroxyoxime extractant and divalent metal ion, respectively. $\mathrm{O}$ represents species in the organic phase, and A indicates species in the aqueous phase.

From Equation 3, it is evident that the equilibrium shift to the right with decreasing hydrogen ion concentration promotes extraction of metals into the organic phase. N902 can therefore be directly added to the leaching solution $(\mathrm{pH}=11.0)$ to extract metals. Using acid extractants, however, it is necessary to adjust the $\mathrm{pH}$ of the leaching solution to neutral to complete the metal extractions. Compared with the use of acidic extractants, N902 simplifies the operational process, shortens the time for complexation, and reduces the cost of the process. 
Table 3. Metals concentrations in N902 extraction phase.

\begin{tabular}{|c|c|c|c|c|c|c|}
\hline Metals & $\mathrm{Cu}$ & $\mathrm{Ni}$ & $\mathrm{Al}$ & $\mathrm{Ca}$ & $\mathrm{Cr}$ & $\mathrm{Fe}$ \\
\hline Content $(\mathrm{g} / \mathrm{L})$ & 6.81 & 13.10 & 0.64 & 0.69 & 0.87 & 0.29 \\
\hline
\end{tabular}

Table 4. Metals concentrations in washing water.

\begin{tabular}{|c|c|c|c|c|c|}
\hline Metals & $\mathrm{Cu}$ & $\mathrm{Ni}$ & $\mathrm{Al}$ & $\mathrm{Ca}$ & $\mathrm{Fe}$ \\
\hline Content $(\mathrm{g} / \mathrm{L})$ & 0.01 & 0.08 & 0.03 & 0.10 & 0.01 \\
\hline
\end{tabular}

\section{Optimum Water Washing Process}

As the recovery of copper and nickel process, free ammonia accumulates in the aqueous phase, contributing to a loss of ammonia and also increases the amount of acid required to extract the metal. A washing process is necessary to enable free ammonia to be recycled and reused.

The $\mathrm{NH}_{3}-\mathrm{N}$ content of the first washing liquor was 5.01 $\mathrm{g} / \mathrm{L}$ and that of the second was $0.031 \mathrm{~g} / \mathrm{L}$, under conditions of a wash phase ratio $\mathrm{A} / \mathrm{O}$ of 2 , a washing time of $20 \mathrm{~min}$, and two stages of water washing. The results showed that about $10 \%$ of the free ammonias was recycled. Purity of the recovered ammonia was high enough that it could be reused as a leaching reagent. This indicates that water washing is highly effective for decreasing the loss of metals in the organic phase (Table 4) and increasing the economic benefits of this recycling technology.

\section{Stripping of Copper and Nickel}

From Equation 3, an increase in hydrogen ion concentration shifts the equilibrium reaction to the left, which promotes the stripping of metal ions. As shown in Table 5, heavy metal ions in the organic phase are relatively easily
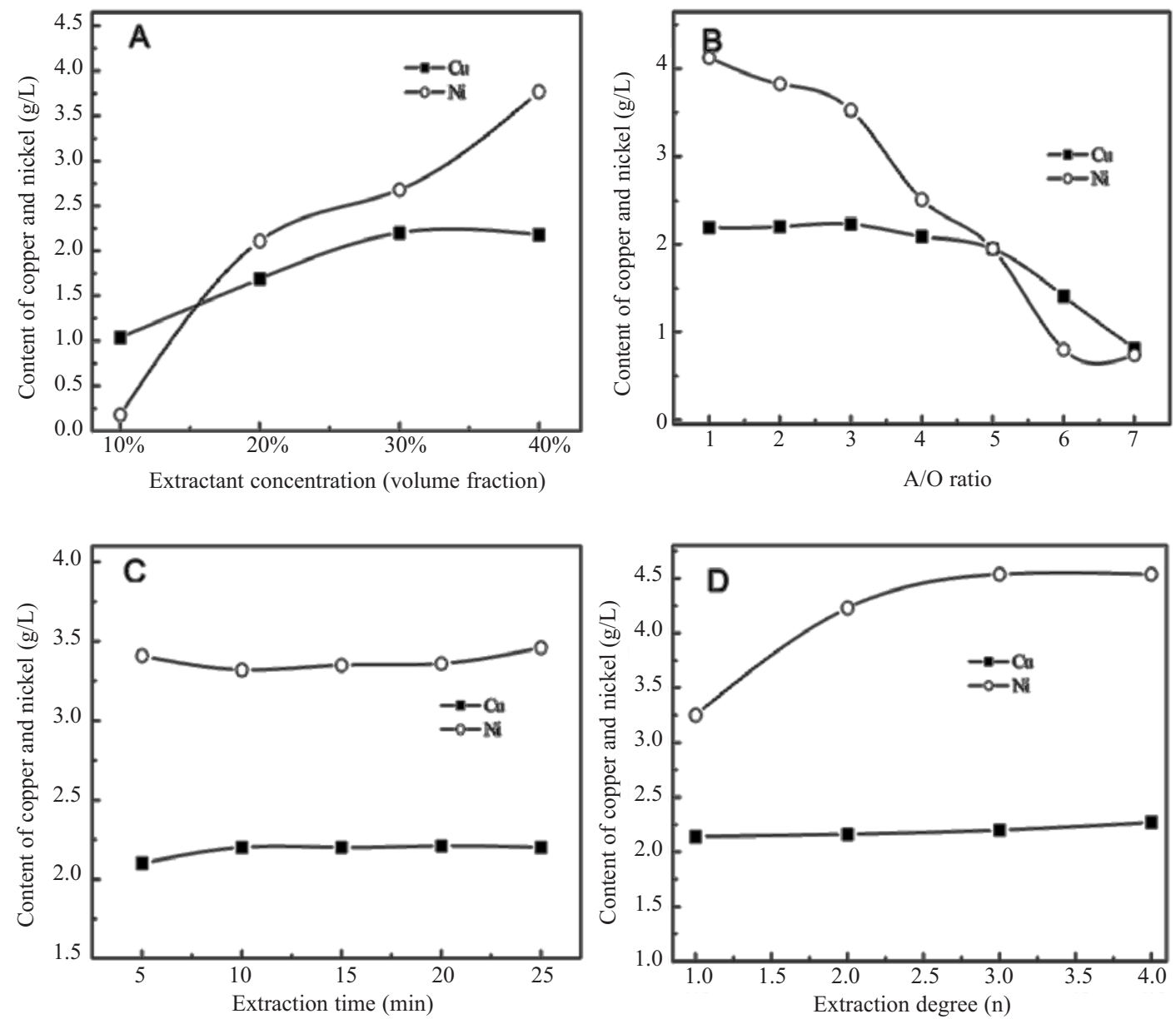

Fig. 3. Effects of the extractant concentration (A), A/O ratio (B), extraction time (C), and extraction degree (D) on extraction of metal ions. (Conditions: $\mathrm{T}=25 \pm 2^{\circ} \mathrm{C}$. A) $\mathrm{A} / \mathrm{O}=3: 1, \mathrm{t}=10 \mathrm{~min}, \mathrm{n}=1 ; \mathrm{B}$ ) extractant concentration $\left.=30 \mathrm{vol} . \%, \mathrm{t}=10 \mathrm{~min}, \mathrm{n}=1 ; \mathrm{C}\right) \mathrm{A} / \mathrm{O}=$ $3: 1$, extractant concentration $=30 \mathrm{vol} . \%, \mathrm{n}=1 ; \mathrm{D}) \mathrm{A} / \mathrm{O}=3: 1, \mathrm{t}=10 \mathrm{~min}$, extractant concentration $=30 \mathrm{vol} . \%, \mathrm{t}=10 \mathrm{~min}$.). 
Table 5. The solubility comparison of various metal salts in water $\left(20^{\circ} \mathrm{C}, \mathrm{g} / 100 \mathrm{~g}\right)$.

\begin{tabular}{|c|c|c|c|c|c|c|c|}
\hline Irons & $\mathrm{Cu}^{2+}$ & $\mathrm{Ni}^{2+}$ & $\mathrm{Fe}^{2+}$ & $\mathrm{Fe}^{3+}$ & $\mathrm{Al}^{3+}$ & $\mathrm{Cr}^{3+}$ & $\mathrm{Ca}^{2+}$ \\
\hline $\mathrm{Cl}^{-}$ & 73 & 66.8 & 62.5 & 91.8 & 70 & very soluble & 74.5 \\
\hline $\mathrm{NO}_{3}^{-}$ & 125 & 94.2 & $134\left(10^{\circ} \mathrm{C}\right)^{*}$ & 138 & 69 & 81 & 129 \\
\hline $\mathrm{SO}_{4}^{2-}$ & 32 & 42.46 & 48 & $20\left(25^{\circ} \mathrm{C}\right)$ & 38 & sparingly soluble & 0.255 \\
\hline
\end{tabular}

*was the solubility of $\mathrm{FeSO}_{4} \cdot 6 \mathrm{H}_{2} \mathrm{O}$

Table 6. Stripping effect of different concentrations of sulfuric acid.

\begin{tabular}{|c|c|c|}
\hline $\begin{array}{c}\text { Concentration of } \\
\text { sulfuric acid } \\
(\mathrm{mol} / \mathrm{L})\end{array}$ & $\begin{array}{c}\text { Concentration of } \\
\text { copper-ion } \\
(\mathrm{g} / \mathrm{L})\end{array}$ & $\begin{array}{c}\text { Concentration of } \\
\text { nickel-ion } \\
(\mathrm{g} / \mathrm{L})\end{array}$ \\
\hline 0.01 & 0 & 0.38 \\
\hline 0.1 & 0.27 & 1.40 \\
\hline 0.2 & 1.14 & 2.09 \\
\hline 0.4 & 2.31 & 3.17 \\
\hline
\end{tabular}

stripped by hydrochloric or nitric acids. The use of sulfuric acid, however, significantly reduces the solubility of the sulfates formed by the impurity ions $\left(\mathrm{Fe}^{2+} / \mathrm{Fe}^{3+}, \mathrm{Al}^{3+}\right.$, etc.), especially calcium and chromic sulfates that are only slightly soluble in water. These sulfates can be removed as precipitates when they are present at high concentrations. The choice of sulfuric acid as a stripping reagent did not, therefore, affect the recycling of the target metals $(\mathrm{Cu}$ and $\mathrm{Ni})$ and impurity ions ( $\mathrm{Fe}, \mathrm{Al}, \mathrm{Cr}$, and $\mathrm{Ca}$ ) and can simultaneously be discarded in the organic phase.

Fig. 4 shows the influence of sulfuric acid concentration on the extent of stripping of copper and nickel from the organic phase. The choice of sulfuric acid as a stripper should be under conditions of $\mathrm{A} / \mathrm{O}=1$ and extraction time of $20 \mathrm{~min}$.

From the data shown in Fig. 4 and Table 6, the concentrations of copper and nickel in the strip liquor increased with increasing sulfuric acid concentration. When the sulfuric acid concentration was a little lower than $0.1 \mathrm{~mol} / \mathrm{L}$, the concentrations of $\mathrm{Cu}$ were lower than that of $\mathrm{Ni}$ in the strip solution, and the metals were easily separated. It has been previously provided that the concentration of sulfuric acid can be strictly maintained at 0.01-0.1 mol/L ( $\mathrm{pH}=0.7-1.7)$, nickel can be striped first from an organic phase containing $\mathrm{Cu}$ and $\mathrm{Ni}$ using a multistage counter-current stripping process [31]. The concentration of the sulfuric acid can then be increased to strip copper from the organic phase. When the sulfuric acid concentration exceeded $5 \mathrm{~mol} / \mathrm{L}$, the stripping of copper exceeded $98 \%$, but formation of a third-phase was also observed, with a middle fraction of emulsified oil appearing, which decreased phase separation. This effect disappeared when the concentration of sulfuric acid decreased to $4 \mathrm{~mol} / \mathrm{L}$, with little impact on stripping of copper (above 97\%). The optimum sulfuric acid concentration was $4 \mathrm{~mol} / \mathrm{L}$ for the stripping of copper. By suitable control of the stripping conditions, copper, and nickel were successively stripped, with the extent of stripping exceeding 98 and 95\%, respectively (Table 7).

To summarize, our results showed that after separation by selective stripping, $96.6 \%$ of total copper and $91.6 \%$ of nickel could be recovered using ammonia/ammonium solution as the leaching agent, N902 as the extractant, and sulfuric acid as the stripping agent. Finally, after washing, evaporation, and crystallization, the strip solution contained copper and nickel industrial-grade sulfates, allowing for direct recycling of copper and nickel content of EPS.

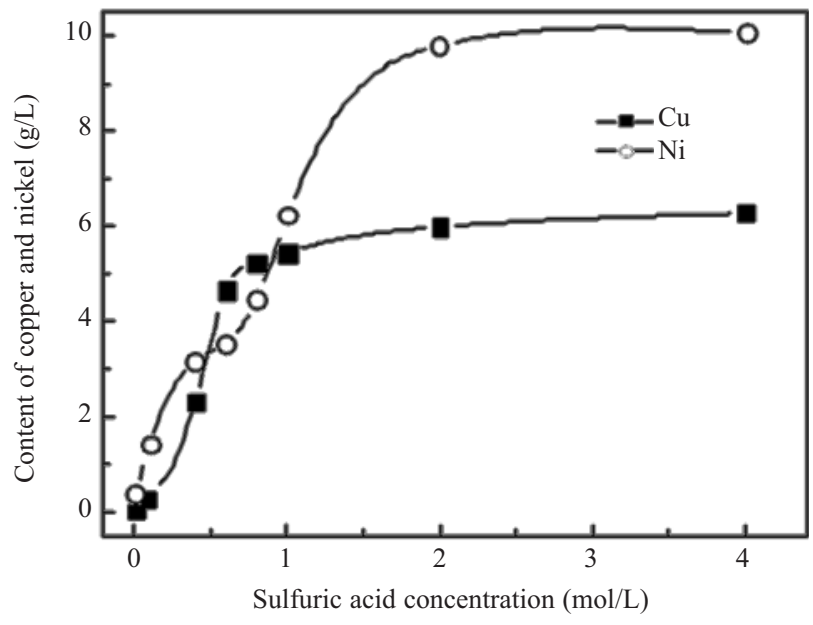

Fig. 4. Effects of acid dosage on stripping of copper and nickel (Conditions: $\mathrm{T}=25 \pm 2^{\circ} \mathrm{C}, \mathrm{A} / \mathrm{O}=1: 1, \mathrm{t}=20 \mathrm{~min}$.).

Table 7. The concentration of metals in the back-extraction solution.

\begin{tabular}{|c|c|c|c|c|c|c|}
\hline Metals & $\mathrm{Ni}$ & $\mathrm{Cu}$ & $\mathrm{Al}$ & $\mathrm{Ca}$ & $\mathrm{Cr}$ & $\mathrm{Fe}$ \\
\hline Ni extract solution $(\mathrm{g} / \mathrm{L})$ & 13.32 & 0.52 & 0.47 & 0.66 & 0.21 & 0.08 \\
\hline Cu extract solution $(\mathrm{g} / \mathrm{L})$ & 0.33 & 7.73 & 0.12 & 0.28 & $\mathrm{ND}$ & 0.017 \\
\hline
\end{tabular}




\section{Conclusion}

In this work we presented the ammonia leaching technology that could effectively separate valuable metals $(\mathrm{Cu}$ and Ni) from EPS. The optimum conditions were determined sequentially to achieve total copper and nickel recoveries of 93.6 and $88.9 \%$, respectively, using ammonia/ammonium solution as the leaching agent, N902 as the extractant, and sulfuric acid as the stripping agent. Moreover, about $10 \%$ of the ammonia could be recycled, thereby lowering the costs of the leaching process. Additionally, this simple process for the recovery of $\mathrm{Cu}$ and $\mathrm{Ni}$ has high selectivity and may be a promising approach for recovering and enriching metals from solid waste at low concentrations, enabling value components to be recycled.

\section{Acknowledgements}

This work was financially supported by a grant from the Science and Technology Commission of Shanghai Municipality (Grant No. 11dz1122200).

\section{References}

1. BAILEY S.E., OLIN T.J., BRICKA R.M., ADRIAN D.D. A review of potentially low-cost sorbents for heavy metals. Water Res. 33, 2469, 1999.

2. ANDREDTTOLA G., CADONNA M., FOLADORI P., GATTI G., LORENZI F., NARDELLI P. Heavy metal removal from winery wastewater in the case of restrictive discharge regulation. Water Sci. Technol. 56, 111, 2007.

3. LI C.C., XIE F.C., MA Y., CAI T.T., LI H.Y., HUANG Z.Y., YUAN G.Q. Multiple heavy metals extraction and recovery from hazardous electroplating sludge waste via ultrasonically enhanced two-stage acid leaching. J. Hazard. Mater. 178, 823, 2010.

4. ESPINOSA D.C.R., TENRIO J.A.S. Thermal behavior of chromium electroplating sludge. Waste Manage. 21, 405, 2001.

5. SMITH C.J., HOPMANS P., COOK F.J. Accumulation of Cr, $\mathrm{Pb}, \mathrm{Cu}, \mathrm{Ni}, \mathrm{Zn}$ and $\mathrm{Cd}$ in soil following irrigation with treated urban effluent in Australia. Environ. Pollut. 94, 317, 1996.

6. CORNU S., NEAL C., AMBROSI J.P., WHITEHEAD P., NEAL M., SIGOLO J., VACHIER The environmental impact of heavy metals from sewage sludge in ferralsols. Sci. Total Environ. 271, 27, 2001.

7. MCLAUGHLIN M.J., ZARCINAS B.A., STEVENS D.P., COOK N. Soil testing for heavy metals. Commun. Soil Sci. Plan. 31, 1661, 2000.

8. WANG Q. Industrial solid waste disposal and recycling, Environmental Science Press, Peking. China. 2006 [In Chinese].

9. ZHANG P., MA Y., XIE F.C. Impacts of ultrasound on selective leaching recovery of heavy metals from metalcontaining waste sludge. J Mater. Cycles Waste. 15, 530, 2013.

10. WU C.H., KUO C.Y., LO S.L. Recovery of heavy metals from industrial sludge using various acid extraction approaches. Water Sci. Technol. 59, 289, 2009.
11. SILVA J.E., PAIVA A.P., SOARES D., LABRINCHA A., CASTRO F. Solvent extraction applied to the recovery of heavy metals from galvanic sludge. J. Hazard. Mater. 58, 113, 2012.

12. JAKOB A., STUCKI S., KUHN P. Evaporation of heavy metals during the heat treatment of municipal solid waste incinerator fly ash. Environ. Sci. Technol. 29, 2429, 1995.

13. SHIH P.H., CHANG J.E., LU H.C., CHIANG L.C. Reuse of heavy metal-containing sludges in cement production. Cement Concrete Res. 35, 2110, 2005.

14. CHOU I.C., KUO Y.M., LIN C., WANG J.W., WANG C.T.,CHANG-CHIEN G.P. Electroplating sludge metal recovering with vitrification using mineral powder additive. Resour. Conserv. Recy. 58, 45, 2012.

15. DACERA D.D., BABEL S. Use of citric acid for heavy metals extraction from contaminated sewage sludge for land application. Water Sci. Technol. 54, 129, 2006.

16. MUZENDA E., RAMATSA I.M., NTULI F., ABDULKAREEM A.S., AFOLABI A.S. Parametric Effects on leaching behavior of nickel-copper matte in ammonia. Particulate Science and Technology: An International Journal. 31, 319, 2013.

17. WANG H.D., ZENG Y.S. Nickel Recovering Technology from Electroplating Sludge in the Way of Ammonia-leaching. Technology \& Development of Chemical Industry. 33, 36, 2004 [In Chinese].

18. ZHU W.P., YE B.Q., YANG Z.H., JIANG, Z.P. Recovery of metal from iron-chromium residue by means of solvent extraction. Environmental Science. 19, 35, 1998 [In Chinese].

19. CHENG J.H., CHEN X., KONG F., ZHOU, Q.F. Recovery of copper and nickel from electroplating sludge by ammonia leaching and hydrogen reduction under high pressure. Environ. Sci. Technol. 33, 135, 2010 [In Chinese].

20. Chinese National Standard GB/T 18918-2002, 2002. Discharge standard of pollutants for municipal wastewater treatment plant.

21. CHOUDHURY A.T.M.A., KENNEDY I.R. Nitrogen fertilizer losses from ricesoils and control of environmental pollution problems. Commun. Soil Sci. Plan. 36, 1625, 2005.

22. DORAISWAMY L.K., DENIZ Üner. Chemical Reaction Engineering: Beyond the Fundamentals. CRC Press, Boca Raton, FL, USA. 2009.

23. MUZENDA E., RAMATSA I. NTULI M., F., ABDULKAREEM A. S., AFOLABI A. S. Parametric effects on leaching behavior of nickel-copper matte in ammonia. Particul. Sci. Technol. 31, 319, 2013.

24. NADIROV R. K., SYZDYKOVA L. I., ZHUSSUPOVA A. K., USSERBAEV M. T. Recovery of value metals from copper smelter slag by ammonium chloride treatment. Int. J. Miner. Process. 124, 145, 2013.

25. ANDREEV A.A., DYACHENKO A.N., KRAIDENKO R.I. Processing of oxidized nickel ores with ammonium chloride. Theor. Found. Chem. Eng. 45, 521, 2011.

26. SILVA J.E., SOARES D., PAIVA A.P., LABRINCHA J.A., CASTRO F. Leaching behaviour of a galvanic sludge in sulphuric acid and ammoniacal media. J. Hazard. Mater. 121, 195, 2005.

27. DANNENBERG R.O., GARDNER P.C., CRANE S.R.. Seidel recovery of cobalt and copper from complex sulfide concentrates. Bureau of Mines Report of Investigations, United States Department of the Interior, Washington DC, USA. 1987. 
28. YOSHINARI B., MINAKO I., HIDETO N. Extraction mechanism of copper (II) with 2-Hydroxy-4-n-octyloxybenzophenone Oxime. Ind. Eng. Chem. Res. 41, 5853, 2002.

29. CARLOS E. O. Valorisation of industrial wastes for the removal of metals and arsenic from aqueous effluents. $\mathrm{PhD}$ thesis, Pollution Research Group, Universitat de Girona, Girona, Spain. 2009.
30. ZHANG G.Z., TONG Z.F., GAO D.M. Study on recovery technology of nickel from electroplating sludge. Environmental Science Survey. 29, 67, 2010 [In Chinese].

31. TAHARA K., ABE Y., SUGATA S., NISHIZAWA H., NISHIKAWA T. SUZUKI H., TAKEUCHI M. Improved apparatus for solid-liquid multi-stage counter-current extraction. J. Chromatogr. A. 1017, 63, 2003. 